\title{
IdENTIFICATION OF SPECIAL CAUSES
}

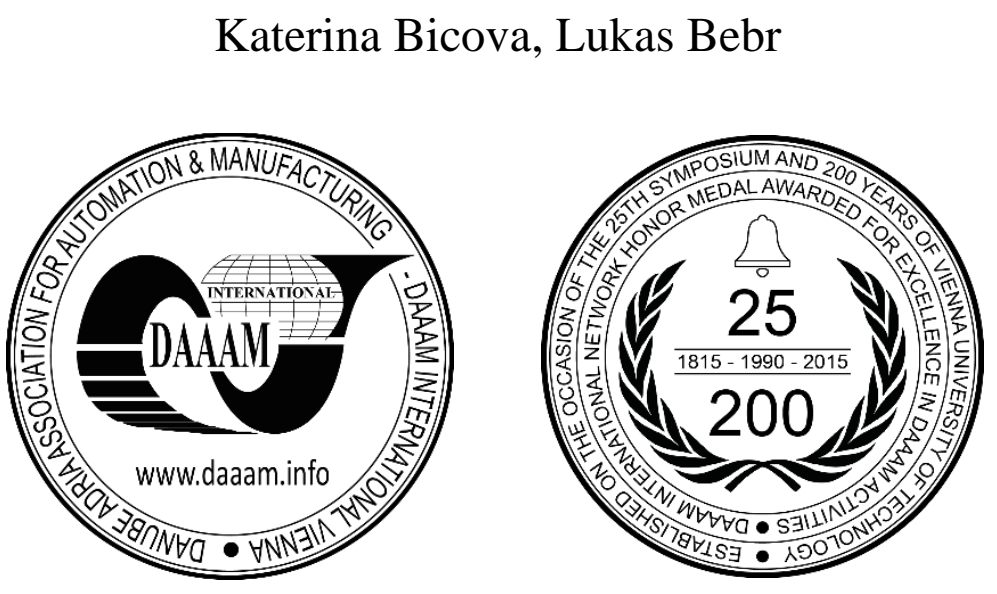

This Publication has to be referred as: Bicova, K[aterina] \& Bebr, L[ukas] (2017). Identification of Special Causes, Proceedings of the 28th DAAAM International Symposium, pp.0379-0383, B. Katalinic (Ed.), Published by DAAAM International, ISBN 978-3-902734-11-2, ISSN 1726-9679, Vienna, Austria

DOI: $10.2507 / 28$ th.daaam.proceedings.053

\begin{abstract}
This paper deals with identifying the special causes of variability, which cause fluctuations in the monitored production process. SPC is used for uncovering these causes. The control diagrams can be described as a simple and effective tool for understanding the process under monitoring and therefore we can rank it as a commonly used tool in industrial practice. Critical criteria for determining the build-up of the control charts are the criteria for determining whether the process is stable or unstable. The aim of the paper is to focus attention on the case, where the process is unstable and the causes of fluctuations beyond the set limits, or the occurrence of other undesirable trends, need to be identified. Because the identification of special causes is essential for process control and further process monitoring and evaluation of the processes.
\end{abstract}

Keywords: SPC; control diagrams; special causes; manufacturing process; evaluation

\section{Introduction}

In today's industry, especially in the automotive industry, it is very important to monitor and follow up primary key production processes. For this purpose a very useful tool is the Statistical Process Control (SPC). It can be said, that SPC is a simple and effective instrument for understanding the process. For evaluation of the devised control charts determining criteria are valid, based on which we can ascertain whether the process is stable or unstable. The aim of this paper is to focus attention on the case where the process is unstable and where it is necessary to identify the causes of fluctuations beyond the established limits or the occurrence of other undesirable trends. The identification of special causes is essential for process control and further process monitoring and evaluation of the process.

Specific or definable causes relate to sources of fluctuation, that aren't permanently affecting the process and producing unexpected changes. These can be either harmful or beneficial.

Detecting the presence of special causes is the role of SPC. Elimination of special causes is then done in the form of:

- local actions (operating staff, operator within the scope of their authority)

- $\quad$ action within the system (these fall under the responsibility of the management).

The specific cause of variability needs to be identified, eliminated and safeguarded, so that it can no longer be repeated. $[1]$.

As has been said, progressive SPC methods are used for detailed analysis of the production process. This ensures the identification of adverse effects and their correlation with the behaviour of the production process. It is a tool that can be used to monitor the long-term stability of the given system and to ascertain whether the monitored process behaves as 
expected. It is possible to assess whether the variability of the parameter is due to random fluctuations, or if it is a special cause. Use is possible everywhere, where the parameter is progressively monitored in time [2,3]

Control charts help by measuring to explain the results from the view of the process dispersion (variability) and also location (mean value of the process). Therefore the control charts are always presented in pairs. The most common pair of charts are $(\mathrm{X}, \mathrm{R})$ charts. These are the values of the sampling mean of the values obtained from the subgroups, which is the process position measure, and the range of values in each subgroup, which is the degree of process dispersion.

These diagrams are suitable tools for measuring process fluctuations the span can be easily calculated and is substantial for small ranges of subgroups. Graphic presentation is desirable in the SPC for its clearness and readability. [4]

\section{Example - a specific solution}

For a specific example of using SPC and evaluating the manufacturing process data from serial production of a simple machined part of a cylindrical shape are used here. The dimensions of the component are controlled by the innovative measurement technology system Equator. This innovative measurement system allows for the required 100\% control, because it is a very precise and used for manufactured components marked in the automotive industry as critical. [9] The basic principle of the measurement process is based on the comparison of the measured part and the etalon. Upon customer agreement the diameter of the component has been determined as the critical feature.

From each day the relevant data are collected from machined parts inspections. In terms of cost-effectiveness and SPC effectiveness, it is important to correctly determine the extent of the logical subgroup and the length of the inspection interval. [5]

The measured data from one shift from $6: 45$ am to $2: 15 \mathrm{pm}$ are divided into subgroups after 15 minutes. Every 15 minutes 10 samples are taken. First, the basic statistical characteristics required for the construction of the control charts for the selected shift respectively given day are stipulated.

\begin{tabular}{|l|c|}
\hline \multicolumn{2}{|c|}{ Calculated statistics for CD: } \\
\hline $\mathbf{n}_{\mathbf{j}}$ & 10 \\
\hline $\mathbf{k}$ (amount of subgrups) & 30 \\
\hline $\mathbf{x}$ bar bar & 24.030180 \\
\hline Me bar & 24.030300 \\
\hline $\mathbf{R}$ bar & 0.005300 \\
\hline $\mathbf{s}$ bar & 0.001668 \\
\hline $\mathbf{2}$ bar & 0.000003 \\
\hline $\mathbf{s}$ tot & 0.001937 \\
\hline $\mathbf{s}$ xbar & 0.000894 \\
\hline
\end{tabular}

Table 1. Calculated statistics for control diagrams

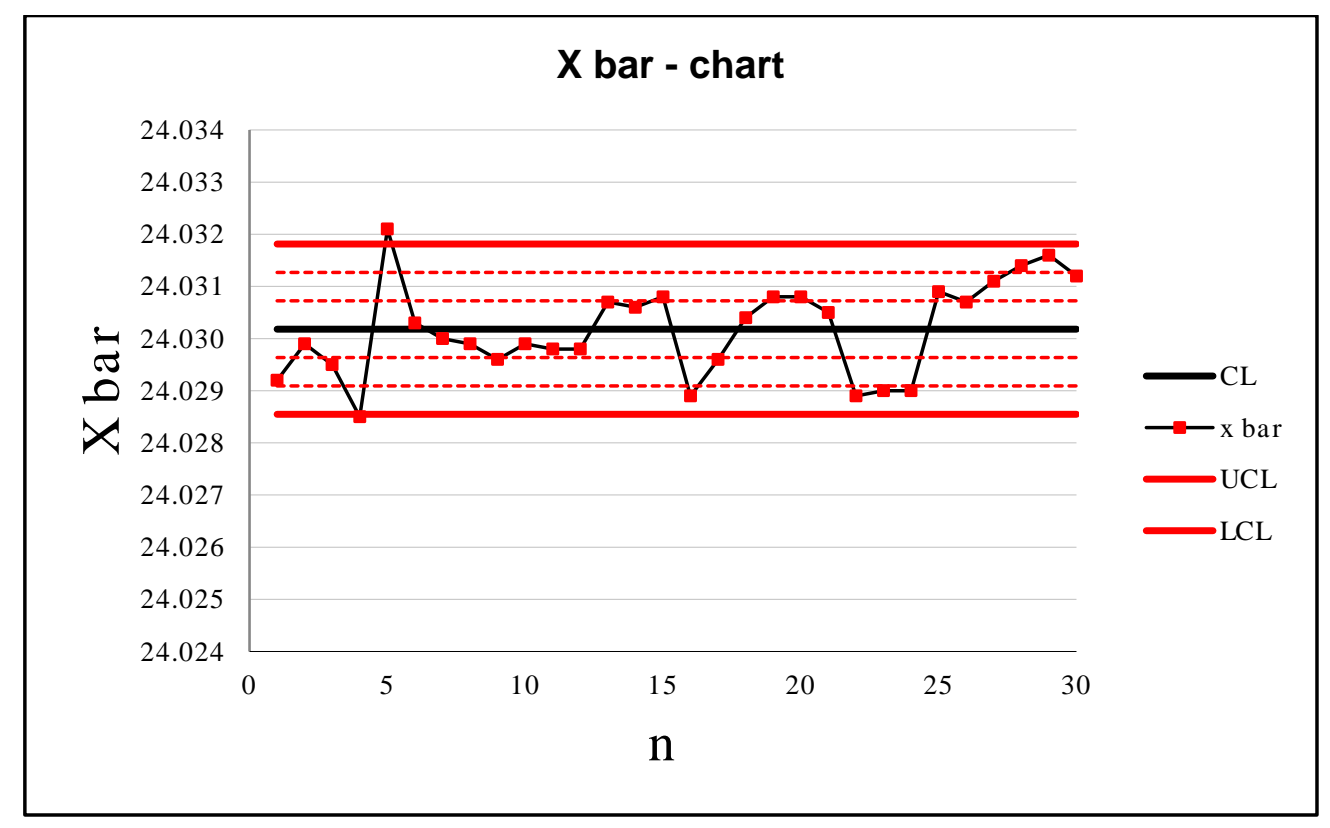

Fig. 1. Control chart for mean 


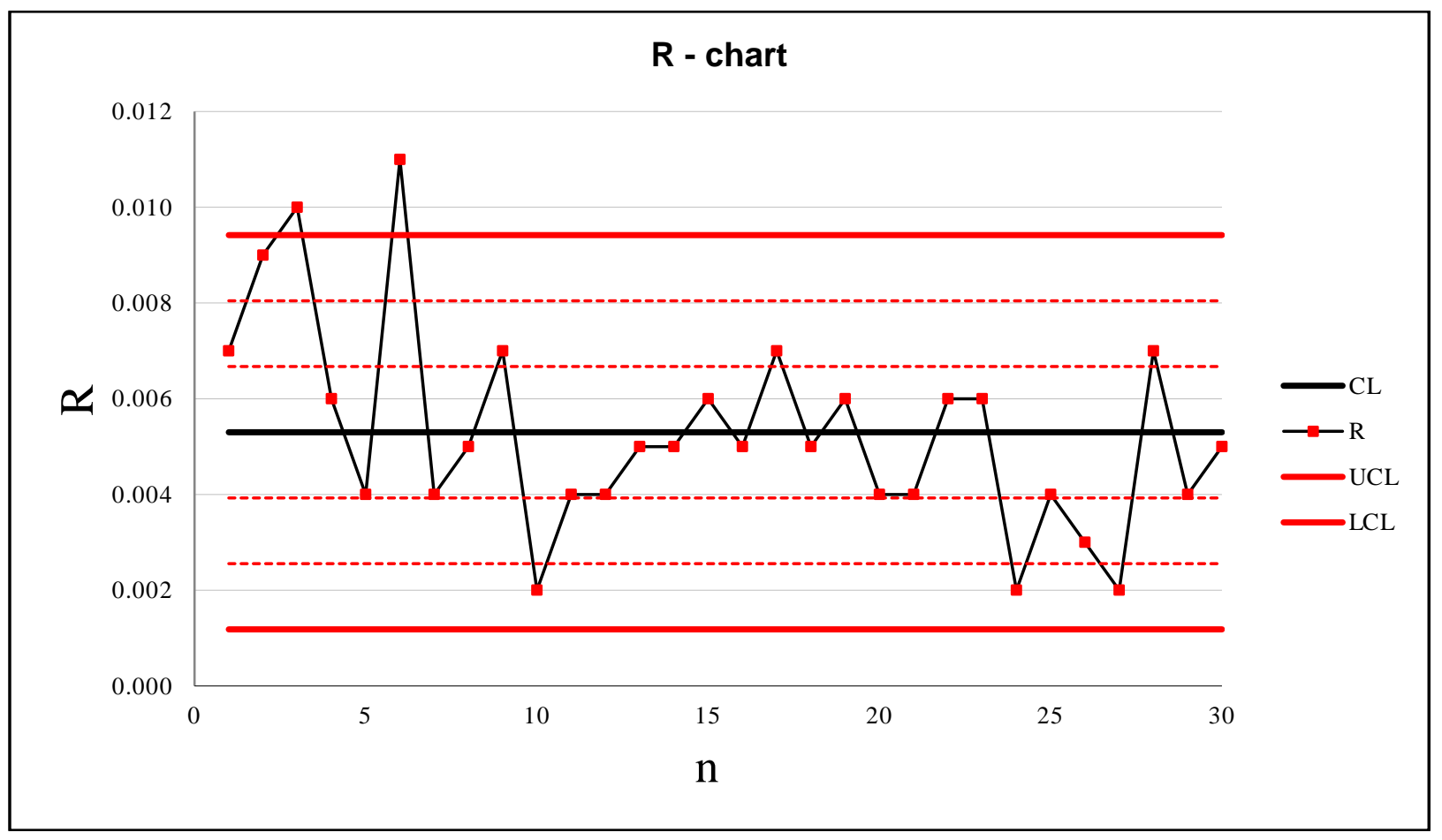

Fig. 2. Control chart for range

After the basic statistical characteristics are determined, control charts are construction. Figure 3 shows an example charts for the average value (mean) and figure 4 for the span.

\section{Solution - Evaluation of the control charts}

For regulation charts other decisive criteria also apply by which we can determine, whether the process is stable or unstable. In order to determine the stability of the process, i. e assessing the need to intervene in the process, e.g. the socalled non-random group tests or special groupings of points or the rules for determining special cases in the charts for the average from ISO 8258: 1998 [6, 7] are used. For example follow figure 3.

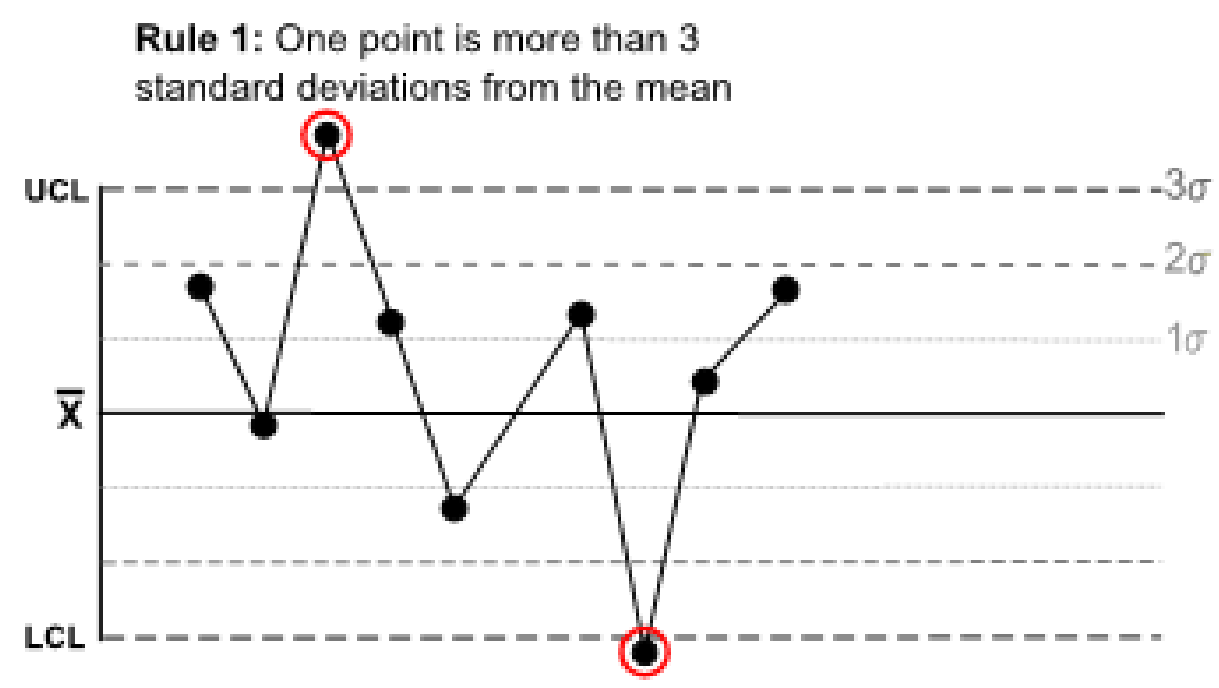

Fig. 3. Example of Nelson's rules [7]

Based on these sources, the built-in charts were evaluated and the following occurred (figure 4):

1. Points exist outside the regulation limits, namely the 4th subgroup under the UCL

2. Points exist outside the regulation limits, namely the 5th subgroup above the UCL. 


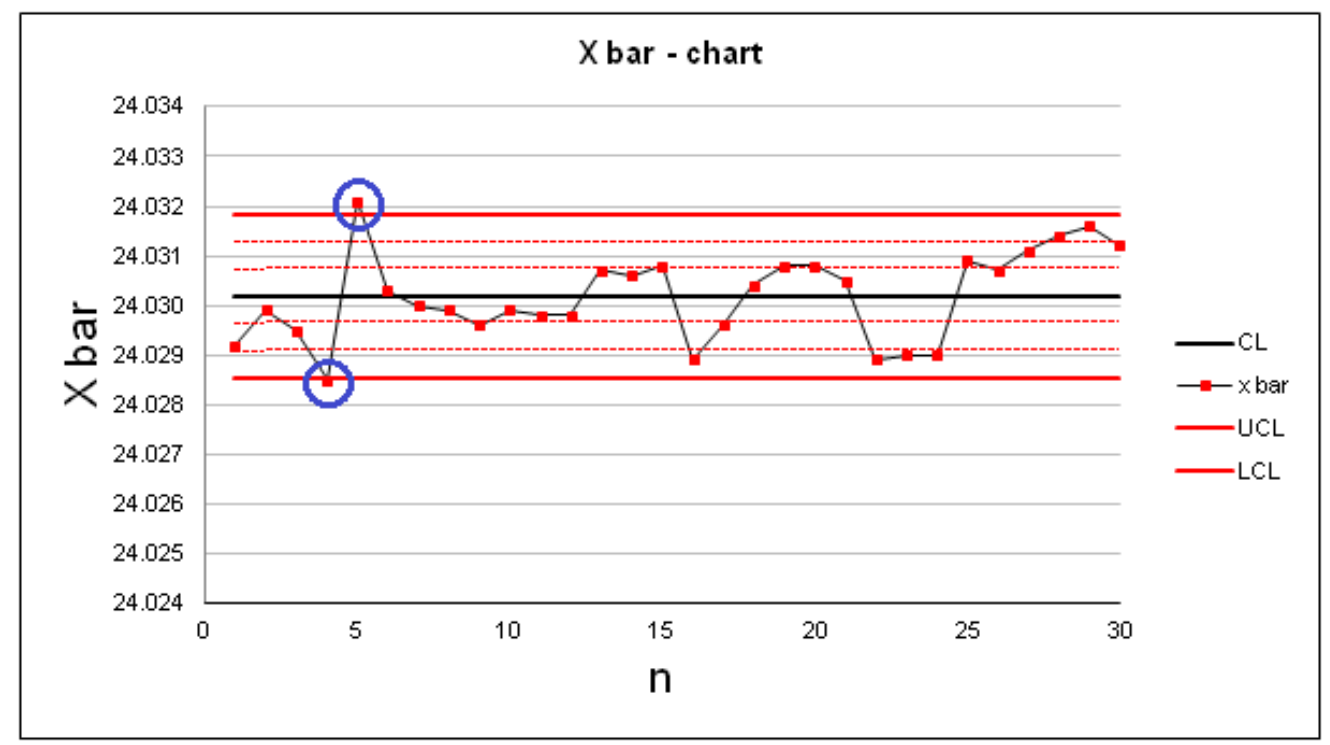

Fig. 4. Control chart with marked points outside the regulation limits

These phenomena can indicate that the process has changed at this point, the measuring system has changed, the control threshold is incorrectly calculated, or the point is poorly plotted in the graph etc.

On the basis of signaling the instability of the process, its causes were identified. One of the basic tools of quality management, namely the Ishikawa diagram (figure 5), was used for this purpose. The most probable causes, such as the used methods, the machine-tool, the cutting tools and the operators present in the production process, and others were analyzed.

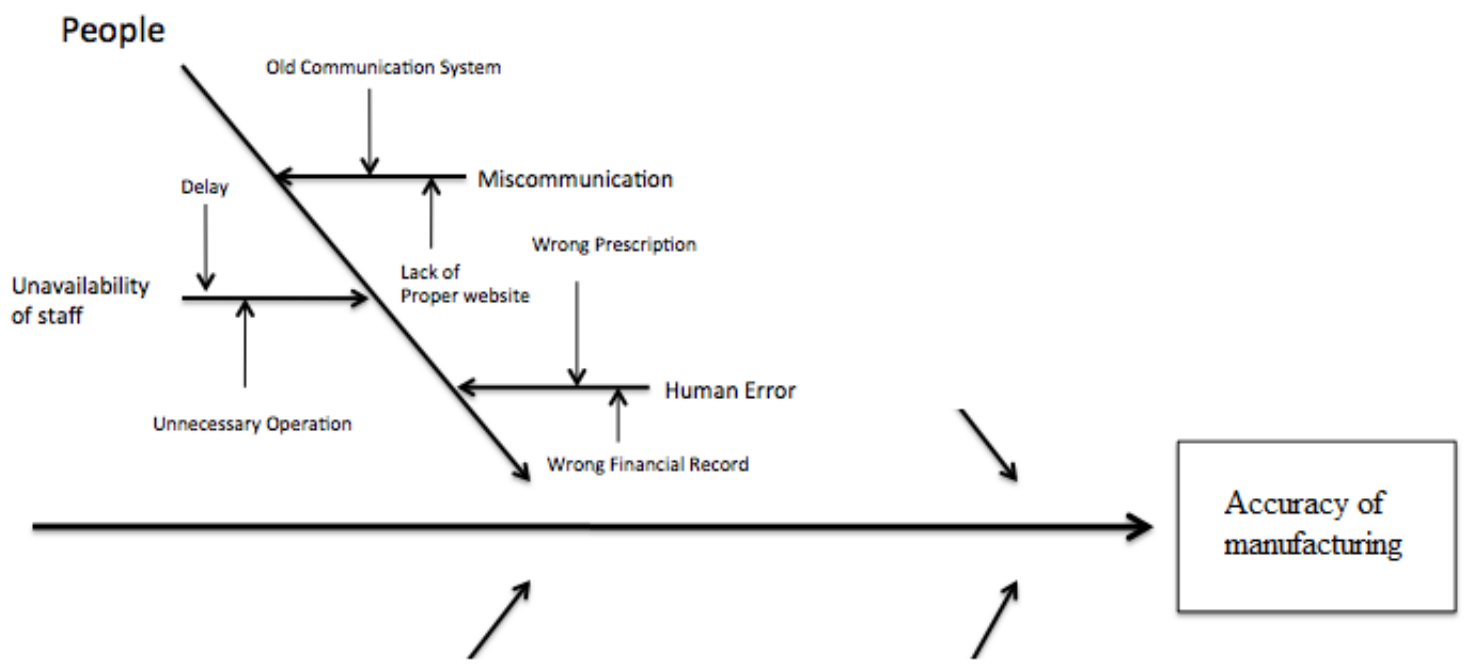

Fig. 5. A sample search for causes

As a result of this analysis, it was found that the cause of process fluctuation, i.e. points beyond the boundaries, was the lack of manufacturing precision of the machining process with respect to the influence of the human factor.

So this is a local cause where the operator made an unintentional error in changing of the cutting tool, caused by his inattention. The cutting tool has a prescribed replacement frequency in the working control procedure always after a specified number of machined pieces. This change was not performed by the operator and therefore a deviation was caused. The change took place later. This deviation was reflected in the accuracy of several manufactured pieces and is also evident in the control charts.

On the basis of the analysis and the identified cause, a corrective action was taken, namely re-training of the attending staff at the machine. If the cause were to repeat, it was proposed to further take another precaution in the form of setting the software of the machine so, that after a certain number of starts of the machining process the tool replacement is requested automatically from the operator.

Manufactured parts with insufficient manufacturing precision were blocked and therefore removed from the sample data set and the control charts were revised. In this case, the process was already stability and capable. 


\section{Conclusion}

Please improve the conclusion. The conclusion must give clear answers on questions: what was the problem, how was it solved, what are the results/solutions, what is solved, what are future plans.

Human beings have a very important and indivisible share in the entire production process. Quality work in this area is very important. However, it is important to realize that high-quality work is not natural, but it is consistent and goodquality preparation, regular training and responsibility of each individual. In the future, the research team would like to concentrate on monitoring the manufacturing accuracy of the machining process with respect to the influence of the human factor. For example, shift work is common in many professions that directly affect the health and safety of others. The quality of life, health, safety and protection at work on shifts and commuting can affect workers in any field and thus their resulting work, e. i. total manufacturing process. [8]

This paper presented a way of evaluating the production process by using data from serial production, where was checked the critical character determined by the customer. From the measured data were created control charts. On the basis of this, the instability of the process was determined and its causes were determined by compiling the Ishikawa diagram. Based on the results was detected a local cause caused by a human factor. Corrective action has been taken and in case of repetition, local measures are proposed directly by setting the software on the machine. With further data collection, the process was already stability and capable.

The human factor has a significant share in the level of precision of production. It is a risk factor that must be remembered in the planning, production and control of machinery, especially in the automotive field, where the precision and quality of production is required on the first place.

\section{Acknowledgments}

This paper includes results created within the SGS-2016-005: Research and development for innovations in the field of mechanical engineering technology - machining technology.

\section{References}

[1] Jarošová E. a D. Noskievičov. (2015). Pokročilejší metody statistické regulace procesu. Grada Publishing a.s. ISBN 978-80-247-5884-8. Praha.

[2] Tabak, John. Probability and statistics. (2004). The science of uncertainty. Fact On File, Inc. ISBN 0-8160-4956-4. New York.

[3] Hrehova S. (2016). Predictive Model to Evaluation Quality of the Manufacturing Process Using Matlab Tools, In Procedia Engineering, Volume 149, 2016, Pages 149-154, ISSN 1877-7058, https://doi.org/10.1016/j.proeng.2016.06.649.

[4] Horálek, V. (1999). QS - 9000 SPC. ČSJ. ISBN 80-02-01293-3. Praha.

[5] Meran, R., John, A., Roenpage, O., Staudter, Ch. (2013). Six Sigma + Lean Toolset (Mindset for Successful Implementation of Improvement Projects). Springer. ISBN 978-3-642-35881-4. Berlin.

[6] ČSN ISO 8258. (1998). Shewhartovy regulační diagramy(Shewharts control charts). Český normalizační institut. Praha.

[7] Nelsonova pravidla pro regulační diagramy. [Online] [Cit.: $23 . \quad 5 . \quad 2017]$ http://upload.wikimedia.org/wikipedia/commons/7/72/Poster_-_Control_Charts_for_Nelson_Rules.svg

[8] Kenneth P. Wright Jr., Richard K. Boganb, James K. Wyatt (2013). Shift work and the assessment and management of shift work disorder (SWD), Sleep Medicine Reviews, Volume 17, Issue 1, February 2013, Pages 41-54 http://www.sciencedirect.com/science/article/pii/S1087079212000251

[9] Martin Melichar, Dana Kubátová. (2015). Processing Data from Automatic Measurement Device, Procedia Engineering, Volume 100, 2015, Pages 899-906, ISSN 1877-7058, http://dx.doi.org/10.1016/j.proeng.2015.01.447 